ISSN: $1858-4837$

E-ISSN: 2598-019X

Volume 14, Nomor 2 (2019),

https://jurnal.uns.ac.id/region

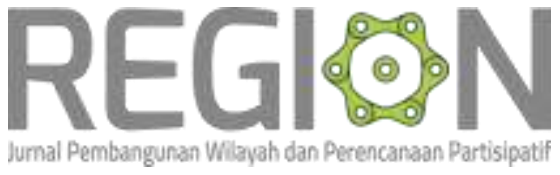

\title{
Kolaborasi Stakeholder Kelurahan dalam Perencanaan dan Pembangunan melalui Integrasi Informasi Geografis
}

\author{
Village Stakeholder Collaboration in Planning and Development \\ through Integration of Geographic Information
}

\author{
Erma Fitria Rini ${ }^{\text {a,b*}}{ }^{*}$ Hakimatul Mukaromah ${ }^{\text {a,b }}$, Murtanti Jani Rahayu ${ }^{\text {a,b }}$ \\ a Prodi Perencanaan Wilayah dan Kota, Fakultas Teknik \\ ${ }^{b}$ Pusat Informasi Pembangunan Wilayah (PIPW), Universitas Sebelas Maret \\ *Corresponding author's email: ermafitria.plano@gmail.com
}

\begin{abstract}
Abstrak
Pemanfaatan sistem informasi geografis menjadi salah satu strategi dalam proses perencanaan kawasan yang berkelanjutan. Dinamika pemanfaatan ruang dapat terekam dan konflik keruangan karena data yang overlap dapat diminimalisir. Pengembangan sistem informasi geografis yang baik memerlukan kolaborasi antar stakeholder di tingkat kelurahan sebagai unit formal terkecil perencanaan kawasan. Tujuan dari penelitian ini adalah untuk mengetahui bagaimana kolaborasi stakeholder di Kelurahan Jagalan dan Kelurahan Sudiroprajan dalam perencanaan dan pembangunan melalui integrasi informasi geografis. Hasil penelitian menunjukkan bahwa belum ada kolaborasi antar stakeholder kelurahan dalam perencanaan melalui integrasi informasi geografis. Kedua kelurahan belum memiliki sumberdaya manusia yang cakap dalam mengoperasikan sistem informasi geografis dan juga belum memiliki perangkat keras dan perangkat lunak dengan spesifikasi yang cukup untuk mengembangkan basis data geospasial kelurahan. Aparat kelurahan masih menggunakan teknik konvensional untuk membangun basis data kelurahan dan belum ada keterlibatan masyarakat sebagai pengguna ruang kota. Disisi lain, aparat kelurahan dan masyarakat di kedua kelurahan memiliki kemauan dan potensi kapasitas individu untuk diberikan pelatihan dalam mengoperasikan dan mengembangkan basis data geospasial kelurahan.
\end{abstract}

Keywords: kolaborasi stakeholder, perencanaan spasial, system informasi geografis

\begin{abstract}
The use of geographic information systems is a strategy in the process of sustainable regional planning. The dynamics of spatial utilization can be recorded and spatial conflict because overlapping data can be minimized. Development of a good geographic information system requires collaboration between stakeholders at village level as the smallest formal unit of regional planning. The purpose of this research is to find out how the collaboration of stakeholders in Jagalan Village and Sudiroprajan Village in planning and development through integration of geographic information. The results of the study show that there is no collaboration between village stakeholders in planning through geographic information integration. Both village do not have competent human resources in operating geographic information systems and also do not have the hardware and software with sufficient specifications to develop the geospatial database. The officials still use conventional techniques to build a village database and there is no community involvement as a user of city space. On the other hand, officials and the community in both village have the willingness and potential of individual capacity to be given training in operating and developing the geospatial database.
\end{abstract}

Keywords: geographic information system, spatial planning, stakeholders collaboration 


\section{PENDAHULUAN}

Pemanfaatan ruang di Kota Surakarta terus mengalami peningkatan seiring dengan pertumbuhan penduduk dan aktivitas di dalamnya. Pertumbuhan pemanfaatan ruang tersebut memerlukan suatu perencanaan kawasan yang berkelanjutan agar tetap tercipta keseimbangan antara aspek sosial, ekonomi, dan lingkungan. Kegiatan perencanaan kawasan memerlukan suatu sistem basis data yang dapat diperbaharui dan digunakan secara efisien. Ketidaktersediaan basis data terkait pemanfaatan ruang kota yang komprehensif merupakan salah satu faktor yang membuka celah tidak sinkronnya potensi dan permasalahan eksisting kawasan dengan perencanaan pemanfaatan ruang. Pemahaman terkait kondisi pemanfaatan ruang eksisting yang diperoleh dari basis data yang detail, bersifat spasial, mudah diakses dan adaptif terhadap pembaharuan merupakan salah satu langkah dalam mewujudkan perencanaan kawasan yang berkelanjutan.

Basis data yang digunakan dalam perencanaan kawasan harus dapat dipertanggungjawabkan tingkat validitasnya dan mampu mewakili kondisi eksisting di lapangan. Pemanfaatan teknologi informasi, khususnya yang bersifat geografis atau geospasial, dalam membangun suatu basis data dapat meminimalisir terjadinya kesalahan atau overlap dalam perencanaan pemanfaatan ruang. Hal tersebut akan memudahkan proses pengambilan keputusan dimana data menjadi input utama dalam pertimbangannya. Kegiatan pemetaan telah lazim dalam perencanaan masyarakat untuk beberapa waktu, seperti penggunaan peta sebagai rangsangan untuk dialog kelompok atau membiarkan komunitas menanamkan ciri-ciri tanah yang signifikan pada peta mereka sendiri dalam lingkungan deliberatif (Wates, 2014).

Kelurahan merupakan unit formal terkecil dalam proses perencanaan pembangunan kawasan. Keterlibatan seluruh stakeholder di tingkat kelurahan sangat dibutuhkan dalam membangun suatu informasi geografis yang dapat dijadikan sebagai basis data dalam perencanaan kawasan yang berkelanjutan. Kolaborasi antar stakeholder, khususnya antara masyarakat dan aparat kelurahan, akan mampu menghasilkan basis data yang detail, komprehensif, dan faktual. Keterlibatan masyarakat dapat mengurangi kemungkinan terjadinya kesalahan dalam perencanaan karena kebijakan yang dibuat berorientasi pada kebutuhan dengan iklim yang kolaboratif (Vaggione, 2013).

Wilayah studi dalam penelitian ini adalah Kelurahan Jagalan dan Kelurahan Sudiroprajan. Pendataan pemanfaatan ruang di kedua kelurahan belum sepenuhnya 
Region, Vol. 14, No.2, Juli 2019: 220-228

melibatkan seluruh stakeholder di masing-masing kelurahan. Pendataan hanya dilakukan oleh aparat kelurahan dengan menghimpun atau memperbaharui data berdasarkan pengamatan di lapangan. Padahal, dalam hal pendataan pemanfaatan ruang, masyarakat merupakan sumber data utama mengingat masyarakat merupakan pengguna (end user) ruang perkotaan, sehingga dapat menjadi sumber daya dalam kegiatan pembaharuan data pemanfaatan ruang di lingkungannya.Di sisi lain, perencanaan yang melibatkan masyarakat secara luas dapat dilaksanakan pada wilayah yang kecil seperti di tingkat kelurahan, sedangkan untuk wilayah yang lebih luas biasanya hanya mungkin melibatkan tokoh masyarakat saja (Tarigan, 2015). Jadi, sangat memungkinkan adanya upaya kolaborasi antara aparat kelurahan dan masyarakat di tingkat kelurahan dalam proses pengembangan basis data untuk perencanaan kawasan.

Keterbatasan kapasitas stakeholder kelurahan dalam penguasaan teknologi berbasis geospasial dalam pendataan pemanfaatan ruang juga menjadi permasalahan yang dihadapi oleh kedua kelurahan. Untuk mewujudkan suatu basis data yang mampu mendukung perencanaan dan pengendalian pemanfaatan ruang yang berkelanjutan diperlukan pengembangan kapasitas stakeholder kelurahan dalam pemetaan wilayah melalui sistem informasi geospasial. Strategi mengembangkan kapasitas sumberdaya instansi teknis perencanaan daerah dengan melibatkan kelompok kepentingan lain adalah strategi kunci untuk mengatasi kekurangan SDM dan upaya untuk menghasilkan perencanaan yang lebih baik (Vaggione, 2013). Hal ini juga untuk memastikan pendataan pemanfaatan ruang perkotaan yang dinamis dilakukan dengan bantuan satu sistem basis data yang dapat diperbaharui dengan efisien dan mudah digunakan. Oleh karena itu diperlukan suatu proses transfer teknologi dengan user interface yang mudah dipahami dan ditransfer pada orang lain dalam bentuk tutorial penggunaan teknologi geospasial.

Selain subjek dalam pendataan pemanfaatan ruang, aspek lain yang penting dalam membangun basis data adalah media yang digunakan. Sampai saat ini, pendataan pemanfaatan ruang di kedua kelurahan yang dilakukan oleh aparat kelurahan masih menggunakan basis data konvensional dan belum berbasis data digital. Keterbatasan teknologi yang dimiliki kelurahan menjadi salah satu faktor penyebabnya. Ketersediaan perangkat, baik perangkat keras (hardware) maupun perangkat lunak (software), yang mampu mendukung dalam pembangunan basis data berbasis geospasial sangat diperlukan sebagai modal awal dalam membentuk sistem informasi geografis kelurahan. 
Erma Fitria Rini, dkk, Kolaborasi Stakeholder...

Kelurahan Jagalan dan Kelurahan Sudiroprajan masuk dalam wilayah administrasi Kecamatan Jebres, Kota Surakarta. Kelurahan Jagalan memiliki luas wilayah 65 Ha dan Kelurahan Sudiroprajan seluas 23 Ha dengan mayoritas penggunaan lahan di kedua kelurahan adalah pemukiman (BPS, 2017). Disisi lain, kedua kelurahan memiliki potensi dalam pengembangan perdagangan dan jasa karena lokasinya yang cukup strategis di pusat Kota Surakarta dengan Pasar Gede sebagai salah satu penarik utama aktivitas. Hal tersebut dapat mendorong terjadinya perubahan pemanfaatan ruang komersil yang sulit dikendalikan dan berpotensi menimbulkan konflik sosial apabila kelurahan tidak memiliki basis data pemanfaatan ruang yang bersifat geografis sebagai salah satu elemen penting dalam perencanaan dan pengendalian pemanfaatan ruang kawasan.

Permasalahan utama yang dihadapi oleh Kelurahan Jagalan dan Kelurahan Sudiroprajan adalah belum adanya kolaborasi antar stakeholder kelurahan dalam pengembangan basis data geospasial yang digunakan sebagai dasar dalam kegiatan perencanaan kawasan. Selain itu, terbatasnya sumberdaya yang dimiliki oleh kelurahan, baik sumberdaya manusia maupun sumberdaya modal/perangkat. Penelitian ini bertujuan untuk mengidentifikasi kapasitas stakeholder kelurahan dan bagaimana kolaborasi yang terjadi terkait pengembangan basis data geospasial untuk digunakan dalam kegiatan perencanaan kawasan.

\section{METODE PENELITIAN}

Metode penelitian yang digunakan dalam penelitian ini adalah metode deskriptif untuk menggambarkan bagaimana kolaborasi stakeholder di kelurahan dalam perencanaan dan pembangunan melalui integrasi informasi geospasial. Metode deskriptif adalah metode yang dapat digunakan untuk menjelaskan atau menganalisis suatu hasil penelitian tetapi tidak dapat membuat kesimpulan yang lebih luas (Sugiyono, 2005). Pengumpulan data dalam penelitian ini menggunakan teknik observasi dan wawancara. Observasi dilakukan dalam mengidentifikasi karakteristik wilayah studi di masing-masing kelurahan dan mengidentifikasi sumber daya masing-masing kelurahan terkait ketersediaan sumberdaya manusia, perangkat keras, dan perangkat lunak dalam upaya integrasi informasi geografis. Wawancara dilakukan untuk mengidentifikasi kapasitas stakeholder kelurahan dan bagaimana kolaborasi yang terjadi dalam perencaanan dan pembangunan melalui integrasi informasi geografis. Wawancara dilakukan terhadap key person di masingmasing kelurahan. 


\section{PEMBAHASAN}

\subsection{Identifikasi Permasalahan Wilayah Studi}

Permasalahan di masing-masing wilayah studi yang terkait dengan kolaborasi stakeholder kelurahan dalam integrasi informasi geografis telah dapat diidentifikasi. Permasalahan yang teridentifikasi di Kelurahan Jagalan antara lain:

1) Belum adanya kolaborasi antara masyarakat dan aparat kelurahan dalam mengintegrasikan informasi geografis

2) Tidak memiliki peta kelurahan yang merepresentasikan informasi geografis sebagai dasar perencanaan kawasan

3) Tidak dapat menyajikan peta sebagai tampilan umum di kantor Kelurahan

4) Tidak memiliki perangkat keras dan perangkat lunak untuk mengoperasikan sistem informasi geografis kelurahan

5) Belum memiliki sumberdaya manusia yang cakap dalam mengoperasikan sistem informasi geografis kelurahan

Permasalahan yang teridentifikasi di Kelurahan Sudiroprajan antara lain:

1) Kurangnya kolaborasi dalam mengintegrasikan basis data geografis antara masyarakat dan aparat kelurahan

2) Tidak mampu menyajikan peta kelurahan yang dijadikan sebagai dasar dalam kegiatan perencanaan dan pembangunan

3) Tidak dapat menyajikan peta yang terbaru sebagai informasi geografis di kantor Kelurahan

4) Tidak memiliki perangkat komputer yang spesifikasinya mampu untuk mengolah data berbasis geografis

5) Tidak memiliki perangkat lunak untuk menyusun basis data secara digital

6) Sumberdaya manusia di tingkat kelurahan belum cakap dalam mengoperasikan sistem informasi geografis

\subsection{Karakteristik Wilayah Studi}

Kelurahan Jagalan dan Kelurahan Sudiroprajan termasuk dalam wilayah administratif Kecamatan Jebres. Luas penggunaan lahan di masing-masing kelurahan dapat dilihat pada Tabel 1 dan Tabel 2 sebagai berikut: 
Erma Fitria Rini, dkk, Kolaborasi Stakeholder...

Tabel 1. Klasifikasi Penggunaan Lahan Kelurahan Jagalan

\begin{tabular}{|c|c|c|}
\hline Jenis Penggunaan Lahan & Luas (Ha) & $\begin{array}{c}\text { Persentas } \\
\text { e }\end{array}$ \\
\hline Industri & 4.113179 & $6.68 \%$ \\
\hline Lapangan & 0.168116 & $0.27 \%$ \\
\hline Pendidikan & 3.374963 & $5.48 \%$ \\
\hline Perkantoran & 1.010435 & $1.64 \%$ \\
\hline Permukiman & 47.072652 & $76.44 \%$ \\
\hline Perusahaan & 5.776243 & $9.38 \%$ \\
\hline Tempat Ibadah & 0.06818 & $0.11 \%$ \\
\hline Total & 61.583768 \\
\hline
\end{tabular}

Penggunaan lahan di Kelurahan Jagalan dan Kelurahan Sudiroprajan sama-sama didominasi oleh permukiman. Bahkan di Kelurahan Jagalan luas permukiman lebih dari tiga perempat luas wilayahnya. Kelurahan Sudiroprajan memiliki luas penggunaan lahan untuk permukiman dan perusahaan yang hampir sama.

Tabel 2. Klasifikasi Penggunaan Lahan Kelurahan Sudiroprajan

\begin{tabular}{|c|c|c|}
\hline Jenis Penggunaan Lahan & Luas (Ha) & $\begin{array}{c}\text { Persentas } \\
\text { e }\end{array}$ \\
\hline Pendidikan & 0.279094 & $1.17 \%$ \\
\hline Perkantoran & 0.340501 & $1.42 \%$ \\
\hline Permukiman & 11.40776 & $47.67 \%$ \\
\hline Perusahaan & 10.9915 & $45.93 \%$ \\
\hline Sungai & 0.380739 & $1.59 \%$ \\
\hline Tanah Kosong & 0.474 & $1.98 \%$ \\
\hline Tempat Ibadah & 0.056891 & $0.24 \%$ \\
\hline Total & \multicolumn{2}{|c|}{23.93049} \\
\hline
\end{tabular}

Lokasi kedua kelurahan yang berada di pusat Kota Surakarta dapat menimbulkan konflik kepentingan dalam penggunaan lahannya. Perlu adanya basis data spasial agar penggunaan lahan di kedua kelurahan dapat dikelola sesuai dengan arah kebijakan perencanaannya.

\subsection{Sumberdaya Sistem Informasi Geografis Kelurahan}

Sumberdaya yang diperlukan dalam mendukung Sistem Informasi Geografis Kelurahan adalah sumberdaya manusia dan juga ketersediaan perangkat penunjang sistem informasi geografis. Sumberdaya manusia yang diperlukan adalah yang mampu mengelola basis data geospasial. Perangkat yang diperlukan adalah perangkat keras (hardware) yang memiliki spesifikasi tertentu dan mampu untuk mengelola data spasial dengan perangkat lunak (software) pengelolaan data berbasis geospasial seperti ArcGIS 10.3. 
Region, Vol. 14, No.2, Juli 2019: 220-228

Sumberdaya manusia di Kelurahan Jagalan dan Kelurahan Sudiroprajan belum ada yang mampu mengoperasikan sistem informasi geografis. Namun, kedua kelurahan telah memiliki inisiatif untuk mengalokasikan sumberdaya manusia sebagai pelaksana pengelolaan sistem informasi geografis. Hal ini dapat menjadi modal dan prasyarat utama untuk keberlanjutan dalam membangun sistem informasi geografis kelurahan. Selanjutnya, diperlukan pelatihan atau tutorial bagi pelaksana pengelolaan sistem informasi geografis di kedua kelurahan agar mampu mengoperasikan sistem informasi geografis.

Ketersediaan perangkat yang mampu mendukung sistem informasi geografis sangat penting dalam membangun basis data spasial. Ketersediaan perangkat yang mendukung SIG di masing-masing kelurahan dapat dilihat pada Tabel 3.

Tabel 3. Ketersediaan perangkat penunjang SIG

\begin{tabular}{|l|c|c|}
\hline \multicolumn{1}{|c|}{ Jenis Perangkat } & Kel. Jagalan & Kel. Sudiroprajan \\
\hline $\begin{array}{l}\text { Perangkat keras (komputer yang mampu } \\
\text { menjalankan aplikasi SIG) }\end{array}$ & Tidak ada & Tidak ada \\
\hline Perangkat lunak (aplikasi SIG) & Tidak ada & Tidak ada \\
\hline Data spasial kelurahan & Tidak ada & Tidak ada \\
\hline
\end{tabular}

Berdasarkan data pada Tabel 3. diketahui bahwa kedua kelurahan belum memiliki perangkat yang mampu mendukung sistem informasi geospasial kelurahan. Upaya untuk menyediakan perangkat SIG diperlukan sebagai modal dalam membangun basis data geospasial kelurahan.

\subsection{Kolaborasi Stakeholder Kelurahan}

\subsubsection{Identifikasi Kapasitas Stakeholder Kelurahan}

Stakeholder kedua kelurahan, yakni aparat kelurahan dan masyarakat di kedua kelurahan belum memiliki kemampuan dalam mengembangkan basis data geospasial. Jumlah aparat Kelurahan Jagalan dan Kelurahan Sudiroprajan masingmasing adalah 8 orang. Tingkat pendidikan aparat kelurahan paling rendah adalah SLTA dan paling tinggi adalah S2. Hal ini menunjukkan bahwa aparat di kedua kelurahan memiliki potensi dalam mengoperasikan dan mengembangkan basis data geospasial kelurahan. Tentunya dengan adanya pelatihan atau transfer knowledge kepada aparat kelurahan.

Masyarakat di kedua kelurahan juga berpotensi untuk ditingkatkan kapasitasnya sehingga dapat ikut serta dalam mengoperasikan dan mengembangkan basis data geospasial kelurahan. Tingkat pendidikan masyarakat di Kelurahan Jagalan 38\% lebih tinggi dari SLTA, begitu pula dengan Kelurahan Sudiroprajan dengan persentase masyarakat yang memiliki pendidikan lebih dari SLTA adalah $47 \%$. Hal 
Erma Fitria Rini, dkk, Kolaborasi Stakeholder...

ini menunjukkan bahwa kapasitas masyarakat di kedua kelurahan cukup untuk dilakukan transfer knowledge dan teknologi.

\subsubsection{Kolaborasi Stakeholder Kelurahan dalam Integrasi Informasi Geografis}

Pengembangan basis data terkait pemanfaatan ruang di kedua kelurahan hanya dilakukan oleh aparat kelurahan. Teknik yang digunakan masih berbasis konvensional dan belum berbasis data digital. Masyarakat belum dilibatkan secara langsung dalam proses pengumpulan dan pembaharuan data. Padahal, masyarakat sebagai pengguna ruang perkotaan dapat dijadikan sebagai subjek sekaligus sumber data pemanfaatan ruang yang faktual dan valid. Kolaborasi antara aparat kelurahan dan masyarakat dalam pengembangan basis data geospasial kelurahan diharapkan dapat menciptakan sistem informasi geografis kelurahan yang dinamis terhadap perubahan pemanfaatan ruang.

Di sisi lain, kedua kelurahan tersebut juga telah memiliki inisiatif untuk mengalokasikan sumberdaya manusia sebagai pelaksana pengelolaan sistem informasi geografis. Hal ini tentunya menjadi modal dan prasyarat utama untuk keberlanjutan dalam membangun sistem informasi geografis kelurahan. Oleh karena itu, kedua kelurahan ini memiliki nilai strategis dalam pengembangan basis data pemanfaatan ruang berbasis informasi geografis dengan mengkolaborasikan seluruh stakeholder kelurahan. Pengembangan sistem informasi geografis ini akan dapat mendukung perencanaan kawasan yang berkelanjutan dan memastikan hasil pembangunan yang lebih tepat sasaran.

\section{KESIMPULAN}

Berdasarkan penelitian yang telah dilakukan, dapat diketahui bahwa belum ada kolaborasi antar stakeholder kelurahan dalam perencanaan melalui integrasi informasi geografis. Kedua kelurahan belum memiliki sumberdaya manusia yang cakap dalam mengoperasikan sistem informasi geografis dan juga belum memiliki perangkat keras dan perangkat lunak dengan spesifikasi yang cukup untuk mengembangkan basis data geospasial kelurahan. Aparat kelurahan masih menggunakan teknik konvensional untuk membangun basis data kelurahan dan belum ada keterlibatan masyarakat sebagai pengguna ruang kota. Disisi lain, aparat kelurahan dan masyarakat di kedua kelurahan memiliki kemauan dan potensi kapasitas individu untuk diberikan pelatihan atau training dalam mengoperasikan dan mengembangkan basis data geospasial kelurahan. Selanjutnya, diharapkan aparat kelurahan dan masyarakat dapat secara kolaboratif mengembangkan data spasial kelurahan untuk dapat dijadikan sebagai basis data dalam kegiatan perencanaan. 


\section{REFERENSI}

BPS. 2017. Kecamatan Jebres dalam Angka Tahun 2017. BPS Kota Surakarta: Surakarta

Sugiyono. 2005. Metode Penelitian Bisnis. Bandung: Alfabeta

Tarigan, Robinson. 2015. Perencanaan Pembangunan Wilayah. Bumi Aksara: Jakarta

Wates, N. 2014. The Community Planning Handbook: how people can shape their cities, town \& villages in any part of the world. New York: Routledge.

Vaggione, Pablo. 2013. Penataan Kota Bagi Para Pemimpin Daerah (Endra S. Atmawidjaja, et.al). Jakarta: Kementerian Pekerjaan Umum dan Perumahan Rakyat (Original work published 2004) 